\title{
Developing necrotizing enterocolitis: retrospective analysis of 1428 preterm infants at a level-III neonatal intensive care unit over a four years period
}

\author{
Ass. Prof. Hakan Ongun, M.D. ${ }^{a}$, Selim Demirezen, M.D. ${ }^{b}$ and Ass. Prof. Meltem Demir, M.D. ${ }^{c}$
}

\begin{abstract}
Aim. Toinvestigate NEC frequency in premature infants and assess risk factors associated with disease-onset and progression to intestinal perforation.

Methods. Retrospective cohort in preterm neonates hospitalized between 2015 and 2018. Perinatal characteristics, clinical features, nutritional data and laboratory outcome were analyzed using SPSS-23 statistical package. Logistic regression was performed to analyze associated risk factors.
\end{abstract}

Results. In 1428 neonates, the rate of developing NEC was $18.28 \%$. Conception with assisted reproductive technology, cesearean section and postnatal-steroids were associated with NEC (OR: 4.056, $95 \%$ CI: 2.810-5.854, OR: 1.961, $95 \%$ CI: 1.321-2.910, OR: 6.422; 95 \% CI: 4.327-9.530). Timing of first enteral feeding was associated to developing NEC, but not to intestinal perforation $(p<0.001, p=0.604)$. Forty-seven of 261 NEC patients $(18 \%)$ have developed intestinal perforation. Antenatal steroids showed to reduce severe consequences $(p=0.001)$. Timing of first enteral feeding and hemodynamically significant PDA were predisposing factors for NEC and low 5-minutes Apgar score for intestinal perforation. (OR: 6.515; $95 \%$ CI: 5.011-8.470; OR: 4.715; $95 \%$ CI: 2.717-8.183; OR: 2.748; 95 \% CI: 1.100-6.866). Mortality was $9 \%$. Developing NEC increased risk of mortality by 2.192 times (95\% CI: 1.4693.271); in intestinal perforation, mortality risk increased to 11.527 (95\% CI: 6.293-21.115).

Conclusion. NEC frequency was $18.28 \%$. Intestinal perforation occurred in $18 \%$ of NEC patients. PDA and delay in first enteral nutrition were predisposing factors for acquiring NEC and low 5-minutes Apgar scores for intestinal perforation.

Key words: necrotizing enterocolitis, nutrition, premature infant, intestinal perforation, Apgar score.

http:/ / dx.doi.org/10.5546/ aap.2020.eng.405

To cite: Ongun H, Demirezen S, Demir M. Developing necrotizing enterocolitis: retrospective analysis of 1428 preterm infants at a level-III neonatal intensive care unit over a four years period. Arch Argent Pediatr 2020;118(6):405-410.

\section{INTRODUCTION}

A healthy enteral nutrition is imperative in the management of premature infants to avoid complications associated with vascular access, sepsis, and adverse effects of parenteral nutrition. ${ }^{1,2}$ Any delays to achieve full nutrition may result in intestinal dysfunction. ${ }^{3}$ However, to establish full enteral feeding in a premature infant is not as easy as expected; it may take one to two weeks depending upon the infant's health status. ${ }^{4}$ The gut immaturity and prematurityrelated co-morbidities contribute to development of feeding problems and intestinal complications including necrotizing enterocolitis (NEC).

NEC is one of the most destructive diseases occurring in preterm infants. ${ }^{3-6}$ The prevalence is 1 to $3 \%$ o live births and accounts for $7.7 \%$ of total admissions to neonatal intensive care units (NICU). ${ }^{5}$ The incidence increases with earlier gestational age (GA) and lower birthweight. ${ }^{6,7}$

The pathogenesis remains to be multifactorial with different disease processes and several endotypes. . $^{3,6}$ Intestinal immaturity, impaired mucosal defense, microbial dysbiosis, circulatory instability of the gastrointestinal tract, are considered to play a role in the pathologic mechanism. ${ }^{3}$ Clinical features are abdominal distension, bilious emesis, gastric residue, bloody stool and abnormal physiological parameters such as apnea, bradycardia, hemodynamic alterations and temperature instability. 3,8

Mortality is estimated between $10 \%$ and $40 \%$; but intestinal perforation and secondary 
complications (severe infections, strictures, stoma complications and short bowel syndrome) contribute to increased mortality as high as $76 \%{ }^{3,9,10}$ Despite the greater survival of very low birth weight (VLBW) neonates, very little progress has been made in the management of NEC patients. ${ }^{1}$ These consequences lead to extreme caution in these infants who are at risk for developing intestinal problems. Identifying NEC at an early onset is crucial, because once it starts, the pathological process is aggresive and difficult to stop. The objective was to investigate NEC frequency in a preterm population from a highlyreferral, tertiary NICU serving to considerably populated territory around Mediterranean region and assess risk factors associated with disease onset and progression to intestinal perforation.

\section{POPULATION AND METHODS}

The single-center, retrospective cohort was conducted in preterm infants (GA $\leq 37$ weeks) admitted between 2015 and 2018. This study was approved by the institution's ethics committee board.
This NICU is a university-affiliated, tertiary, 34-bed center; neonatal care is provided with the supervision of board-certified neonatologists and nursing resource has a 1:4-1:5 nurse-topatient ratio. Annual admission rates are 850-1100 newborns per year and preterms constitute $35 \%-50 \%$ of the admissions. The patient population consists of neonates with $\mathrm{GA} \geq 23$ weeks, major congenital anomalies and those who require surgical interventions (cardiac, neurosurgical, abdominal). Multidisciplinary approach (pediatric subspecialties and surgical consultants) has led this NICU to become one of the highest referral centers; approximately half of the admissions consist of postnatal-transfers.

Patient data was extracted from hospital database and screened for ICD-codes 'prematurity' and 'NEC'. Exclusion criteria were intestinal anomalies (e.g. meconium peritonitis, volvulus, atresia) and spontaneous intestinal perforations confirmed by laparotomy. ${ }^{11}$ Patients were divided into two main groups as, infants with NEC (defined by modified Bell's criteria) ${ }^{8}$ and control group (infants without

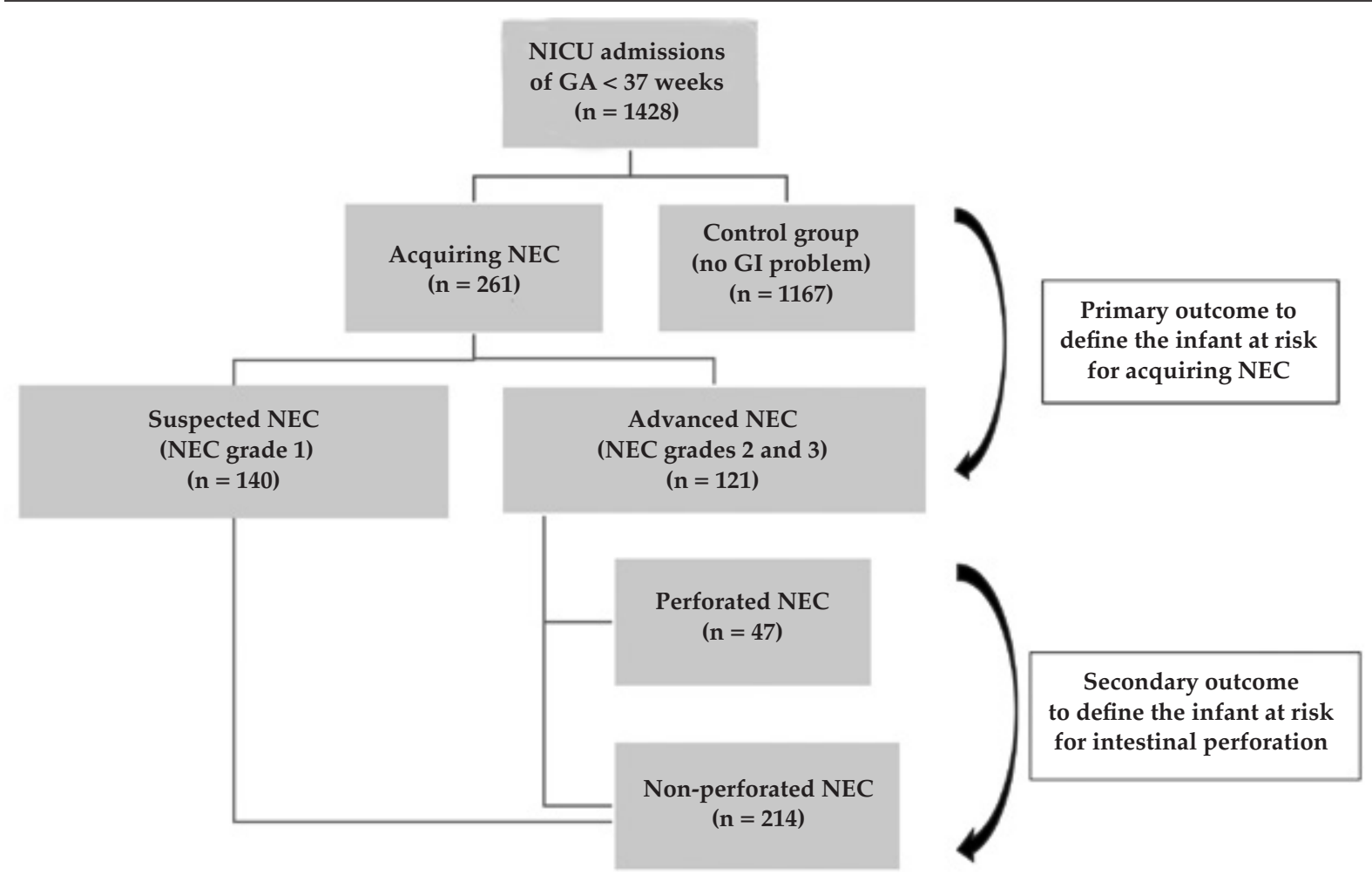

GI: gastrointestinal, NEC: necrotizing enterocolitis. 
intestinal problems). The subcategorizations of NEC patients were based on (i) disease severity (suspected-NEC: grade-1 NEC, advanced-NEC: grade 2-3 NEC) and (ii) intestinal perforation confirmed by $X$-ray and surgery (non-perforations versus intestinal perforations).

We have investigated the perinatal characteristics, clinical features and laboratory outcome. Respiratory distress syndrome (RDS), invasive mechanical ventilation (MV) and noninvasive respiratory support (nasal-CPAP), hemodynamically significant patent ductus arteriosus (echocardiographically-confirmed PDA requiring ibuprofen and/or surgery), congenital heart disease conditions (CHD) other than PDA, intraventricular hemorrhage (IVH) and sepsis (defined by Vermont Oxford criteria) ${ }^{12}$ was collected from the medical files. Complete blood cell count (CBC), C-reactive protein (CRP) and blood gas analysis obtained at the day of initial symtoms were evaluated for early signs of abnormalities.

Enteral nutrition was delivered to all neonates according to the institutional nutrition protocol (see Appendix for the protocol based on Turkish Neonatal Society guideline). ${ }^{13}$ Nutritional variables including timing of first enteral feeding, use of preterm formula, age onset of first intestinal symptoms, duration of fasting and parenteral nutritions were recorded. We have to mention Turkish laws do not govern the use of donor milk when the mother's milk is not available; in absence of mother's milk, undiluted preterm formulas are used.

SPSS-23 program was used for descriptive analysis of variables, central tendency and dispersion of quantitative variables. Following normality assumption (Kolmogorov-Smirnov test), we used Mann Whitney-U or Student-t test to test the difference between two groups; Kruskal Wallis or One-way analysis of variance (followed by posthoc comparisons by Bonferroni or Tamhane test) were performed for analysis within three groups. We used logistic regressions to predict the odds of acquiring NEC and intestinal perforation. Variables were expressed as percentage (\%), mean \pm standard deviation (SD) or median (interquartile range) and odds ratios (OR) and $95 \%$ confidence intervals (CI). P value of less than 0.05 was considered significant.

\section{RESULTS}

Of 1428 preterm deliveries, $261(18.28 \%)$ infants were diagnosed with NEC. Figure 1 presents the flowchart of the study population. Postnatal transfers constituted $32.1 \%$ of suspected-NEC and $43 \%$ of advanced-NEC patients. Many of the perinatal characteristics did not show any significance (Annexes 1 and 2). Small for gestational age (SGA) and young maternal age were associated with suspected$\operatorname{NEC}(p=0.033, p=0.005)$. On the other hand, cesearean section (CS) was the frequent mode of birth delivery in the infants with advanced-NEC $(\mathrm{p}=0.001)$. Conception with assisted reproductive technology (ART), CS delivery and postnatalsteroids were associated with acquiring NEC (OR: 4.056; 95 \% CI: 2.810-5.854; OR: 1.961; $95 \%$ CI: $1.321-2.910$ and OR: 6.422; $95 \%$ CI: 4.327-9.530 respectively). Inversely, antenatal steroids were associated with lower rate of advanced-NEC $(p=0.001)$, but the influence was not apparent for mild stage of the disease ( $p=0.157$ for suspectedNEC). Timing of first enteral feeding and hemodynamically significant PDA were the major determinants of predisposing NEC (OR: 6.515,

TABLE 1. Multivariate regression model for acquiring NEC*

\begin{tabular}{|c|c|c|c|c|}
\hline & \multicolumn{4}{|c|}{$95 \%$ CI for EXP (B) } \\
\hline & $\operatorname{Exp}(B)$ & Lower limit & Upper limit & $p$ \\
\hline PDA & 4.715 & 2.717 & 8.183 & $<0.001$ \\
\hline First enteral feeding & 6.515 & 5.011 & 8.470 & $<0.001$ \\
\hline RDS & 3.538 & 2.238 & 5.594 & $<0.001$ \\
\hline CS delivery & 2.031 & 1.182 & 3.490 & 0.010 \\
\hline Mode of conception - ART & 1.434 & 0.791 & 2.600 & 0.235 \\
\hline Low 5-min Apgar score & 0.931 & 0.534 & 1.624 & 0.801 \\
\hline Postnatal steroids & 0.900 & 0.454 & 1.782 & 0.762 \\
\hline
\end{tabular}

*Acquiring NEC refers to the total sum of patients with suspected and advanced NEC. The model did not include gestational age and birth weight due to significant collinearity. The model's Nagelkerke R²: 0.673, sensitivity: $81.5 \%$ and specificity $97.2 \%$. Abbreviations: PDA: patent ductus arteriosus, RDS: respiratory distress syndrome, CS delivery: caesarean section, ART: assisted reproductive technology. 
$95 \%$ CI: 5.011-8.470 and OR: 4.715, $95 \%$ CI: 2.7178.183; Table 1). Infants with advanced-NEC have shown abnormal laboratory diagnostics as significant thrombocytopenia and leukocytosis at the early stages of intestinal symptoms $(\mathrm{p}=0.003$, $\mathrm{p}<0.001$ ).

Forty-seven (18\%) neonates have developed intestinal perforation. Annex 3 shows the perinatal characteristics based on intestinal perforations. In the univariate analysis, birthweight less than 750 grams, invasive MV and low 5-minutes Apgar score have presented the highest odds for developing intestinal perforation (OR: 12.010; 95 \% CI: 5.760-25.080; OR: 10.851, 95 \% CI: 3.26736.045; OR: 4.827, 95 \% CI: 2.439-9.552). Even if the association between first enteral feeding and acquiring-NEC has been shown, the impact of first enteral nutrition was not apparent for developing intestinal perforation $(\mathrm{p}=0.604)$. Instead, the age onset of initial intestinal symptoms have shown collinearity with disease severity (suspected-NEC: 13 days, advanced-NEC: 18 days, perforations: 19 days). After adjusted for birthweight, low 5-min Apgar score was identified the single independent risk factor for developing intestinal perforation (OR: 2.748, 95 \% CI: 1.100-6.866; Table 2).

Overall mortality rate was $9 \%$. Mortality has increased when the infants have developed severe disease in the form of advanced NEC and intestinal perforations $(27.3 \%, 48.9 \%)$. In preterm infants, acquiring NEC increased the risk of mortality by 2.192 times (95\% CI: 1.469-3.271). In the event of intestinal perforation, the odds increased to 11.527 (95\% CI: 6.293-21.115).

\section{DISCUSSION}

Advances in neonatal care have increased survival in preterm deliveries; however the same situation cannot be valid for gastrointestinal morbidities. ${ }^{14,15}$ The evaluation of 1428 premature infants have shown, I) $18.3 \%$ of NEC frequence and $8.5 \%$ of progression to severe disease, II) mode of conception and CS delivery were associated with acquiring NEC, III) timing of first enteral feeding and hemodynamically significant PDA were identified as risk factors for the disease; IV) intestinal perforations have mainly occurred at birthweights < 750 grams; V) low 5-min Apgar score was the single independent predictor for intestinal perforation.

In order to make progress in the management of NEC, we first need to understand the patholophysiology of the disease. ${ }^{3}$ Intestinal immaturity, microbial dysbiosis, circulatory instability of intestinal tract and ischemia, form the multifactorial basis of NEC. ${ }^{2,3,15}$ Small for gestiational age, low Apgar scores, invasive $\mathrm{MV}$, empiric antibiotics, formulary nutrition, and PDA are some of clinical features associated with disease progression. ${ }^{3,6}$ Hemodynamically significant PDA and low Apgar score were identified as the leading cause of acquiring NEC and its severe consequences (intestinal perforation) in this study. Both results support the fact that intestinal ischemia and circulatory instability are important aspects of inflammatory pathway in developing NEC and intestinal perforations.

The role of microbial dysbiosis on mucosal injury has also been demonstrated in NEC. ${ }^{16,17}$ In order to achieve a healthy, functioning gut in preterm infant, intestinal maturation requires commensial relationship with natural microbiota. After birth, gastrointestinal tract is colonized with organisms more rapidly in vaginal birth compared to CS delivery. Even if, the role of CS in developing NEC has not been confirmed in studies, there is evidence suggesting that altered intestinal flora might involve in the pathophysiologic mechanism. ${ }^{7,16-18}$ The impact of CS on acquiring disease was only evident

TABLE 2. Multivariate logistic regression model for intestinal perforations

\begin{tabular}{lcccc}
\hline & \multicolumn{4}{c}{ 95 \% CI for EXP (B) } \\
& Exp (B) & Lower limit & Upper limit & $p$ \\
\hline Low 5-minutes Apgar score & 2.748 & 1.100 & 6.866 & $\mathbf{0 . 0 3 1}$ \\
Hemodynamically-significant PDA & 0.471 & 0.173 & 1.285 & 0.142 \\
Intraventricular hemorrhage & 0.701 & 0.286 & 1.721 & 0.439 \\
Invasive mechanical ventilation & 1.799 & 0.464 & 6.969 & 0.395 \\
Birthweight & 0.989 & 0.985 & 0.993 & $<0.001$ \\
\hline
\end{tabular}

The models Nagerkerke $R^{2}: 0.618$; sensitivity: $79.6 \%$; specificity: $95.8 \%$. 
in patients with advanced-NEC. This outcome has verified the need for advanced microbiota research to explore the causality of CS delivery and development of NEC..$^{15}$ Nevertheless, to prevent this fatal disease, the idea of promoting vaginal birth might be conceived for preterm deliveries considering the pros and cons of the infants' health status. This assumption is especially important for countries such as Turkey, Mexico, Chile and Korea because they ranked the top four countries with the highest CS delivery rates among the Organisation for Economic Cooperation and Development (OECD) countries. ${ }^{19}$

NEC is inversely proportional with GA and birthweight. 6,7 The incidence is $12 \%$ for birthweights 500-750 grams and there is a reciprocal decrement of $3 \%$ for every 250 grams increase at birthweights. ${ }^{20}$ Of note, we have to mention overall increase in developing NEC for infants less than 1000 grams in the present study. We assumed the discrepancy with the previous reports is due to the explicitly populated postnatal transfers and the nursing resource utilization. Providing multidisciplinary care makes the study center one of the highest referral NICUs and many outborn preterms are postnatally transferred to our unit in the event of clinical deterioration or surgical intervention. For this matter, we believe the numbers would not reflect true NEC incidence. Moreover, being a high-referral center has the disadvantage of over-patient accommodation reaching $100 \%$ or more capacity. Even if neonatal care is provided to new patients in different beds, there is the risk of insufficient nursing-resource utilization, which is a well-known predictor of adverse outcome in premature neonates. ${ }^{21,22}$ Improving nursing provision would help to increase the quality of perinatal care. Thus, the prognosis of low birthweighed infants would be more promising at NICUs of middle to low-income countries.

Early enteral nutrition with breastmilk is crucial for preterms' growth. ${ }^{1}$ It reduces NEC, prevents villous atrophy, stimulates intestinal peristalsis and microbiota. ${ }^{2}$ International consensus is to initiate early trophic nutrition and achieve full enteral nutrition by the end of one to two weeks depending on birthweight. ${ }^{4}$ The duration to reach full enteral feeding has been documented between 10 to 34 days at different studies and regarded as a surrogate marker of gastrointestinal tolerance., ${ }^{3,4}$ However, considerable heterogeneity exists on feeding practices of VLBW neonates. ${ }^{23}$ Controversial data exists on slow or fast advancement in volume of daily intake; recently, 2017 Cochrane database has documented no reduced risk for NEC at slow or fast advancements. ${ }^{24}$ Our institution's nutrition protocol consists of early trophic nutrition with breastmilk (if absent, undiluted preterm formula) and daily advancements in presence of gastointestinal tolerance. Unfortunately, absent nutritional data of the postnatal transfers has hampered to examine the influence of daily nutrition intakes (slow or fast volume increase) on acquiring NEC. Instead, we have observed the timing of first enteral feeding on developing NEC. Each day of delays in enteral nutrition had increased odds of acquiring the problem by 6.515 times. However, the similar outcome was not evident for intestinal perforations. The topic regarding this subject is contradictory: two recent studies have concluded irrelevancy between the timing of first nutrition and NEC (or disease severity); ${ }^{3,6}$ while Moss et al. have shown the relation between delayed enteral feeding and impaired gut and NEC development. ${ }^{25}$ Apparently, delays in enteral nutrition caused by unstable cardiorespiratory dynamics in the first days of life anticipates the future intestinal problems in the neonate; but the pathological process to intestinal perforation is more complex than estimated.

Investigations have tried to create predictive panels to identify advanced-NEC and the necessity of surgical interventions. ${ }^{26}$ Thrombocytopenia, white blood cell count (WBC) abnormality, elevated CRP and blood glucose levels have been found in intestinal perforations. ${ }^{9}$ The analysis to predict intestinal perforations have pointed out early thrombocytopenia, elevated WBC and metabolic acidosis in the deteriorating process, but it was not clear whether the consequent laboratory alterations have accompanied a concomitant infection (sepsis) or not. Even if the diagnostic tools have failed to predict suspected-NEC, they have appeared to be early warning signs to guide health-care providers in estimating severe NEC consequences.

Mortality incidence was consistent with prior publications reporting between $10 \%$ to $40 \%$ (reaching up to $50 \%$ at surgical NEC). ${ }^{3,27}$ The odds of mortality for total sum of NEC patients were 2.192 and raised in presence of intestinal perforations.

Limitations of the study are the retrospective design and single-center research. The absence 
of data on daily nutrition intakes and feeding intervals were other limitations. The diagnostic analysis was also restricted to early stages of initial intestinal symptoms and we did not obtain the subsequent laboratory measures (measuring the predictive performance of laboratory outcome was beyond the scope of this article). Despite the limitations, the strength of this study can be emphasized as the controlled nature and large dataset including 1428 preterm newborns from a highly populated referral NICU. Besides, the study design has consisted of each stage from mild stage to advanced NEC and intestinal perforations.

\section{CONCLUSION}

NEC frequency was $18.28 \%$ in the present study. Of them, $18 \%$ have developed intestinal perforation. Hemodynamically significant PDA and delays in first enteral feeding have increased the risks of acquiring NEC and low 5-minutes Apgar score remained to be the single independent predictor of intestinal perforation.

\section{REFERENCES}

1. Neu j. Necrotizing Enterocolitis: The Future. Neonatology. 2020; 10:1-5.

2. Caplan MS. Necrotizing Enterocolitis in Preterm Infants is Related to Enteral Feeding, But the Mechanisms Remain Uncertain and Have Changed Over Time. Curr Pediatr Rep. 2014; 2(4):241-7.

3. Knell J, Han SM, Jaksic T, Modi BP. Current Status of Necrotizing Enterocolitis. Curr Probl Surg. 2019; 56(1):11-38.

4. Binchy Á, MooreZ, Patton D. Feeding Intervals in Premature Infants $\leq 1750 \mathrm{~g}$ : An Integrative Review. Adv Neonatal Care. 2018; 18(3):168-78.

5. Stoll BJ, Hansen NI, Bell EF, Walsh MC, et al. Trends in Care Practices, Morbidity, and Mortality of Extremely Preterm Neonates, 1993-2012. JAMA. 2015; 314(10):1039-51.

6. Adams M, Bassler D, Darlow BA, Lui K, et al. Preventive strategies and factors associated with surgically treated necrotising enterocolitis in extremely preterm infants: an international unit survey linked with retrospective cohort data analysis. BMJ Open. 2019; 9(10):e031086.

7. Denning NL, Prince JM. Neonatal intestinal dysbiosis in necrotizing enterocolitis. Mol Med. 2018; 24(1):4.

8. Overman RE, Criss CN, Gadepalli SK. Necrotizing enterocolitis in term neonates: A different disease process? J Pediatr Surg. 2019; 54(6):1143-6.

9. Yu L, Tian J, Zhao X, Cheng P, et al. Bowel Perforation in Premature Infants with Necrotizing Enterocolitis: Risk Factors and Outcomes. Gastroenterol Res Pract. 2016; 2016:6134187.

10. Hull MA, Fisher JG, Gutierrez IM, Jones BA, et al. Mortality and management of surgical necrotizing enterocolitis in very low birth weight neonates: a prospective cohort study. J Am Coll Surg. 2014; 218(6):1148-55.
11. Gordon P, Attridge J. Understanding Clinical Literature Relevant to Spontaneous Intestinal Perforations. Am J Perinatol. 2009; 26(04):309-16.

12. Vermont Oxford Network. Manual of Operations: Part 2 Data Definitions \& Infant Data Forms Vermont Oxford Network Release 23.2. 2019:101. [Accessed on January 17, 2020]. Available at: https://vtoxford.zendesk.com/hc/ en-us / articles / 360013115393-2019-Manual-of-OperationsPart-2-Release-23-2-PDF

13. Kültürsay N, Bilgen H, Türkyılmaz C. Turkish Neonatal Society guideline on enteral feeding of the preterm infant. Turk Pediatri Ars. 2018; 53(1):109-18.

14. Wang AY, Chughtai AA, Lui K, Sullivan EA. Morbidity and mortality among very preterm singletons following fertility treatment in Australia and New Zealand, a population cohort study. BMC Pregnancy Childbirth. 2017; 17(1):50.

15. Berkhout DJC, Klaassen P, Niemarkt HJ, de Boode WP et al. Risk Factors for Necrotizing Enterocolitis: A Prospective Multicenter Case-Control Study. Neonatology 2018; 114(3):277-84.

16. Warner BB, Deych E, Zhou Y, Hall-Moore C, et al. Gut bacteria dysbiosis and necrotising enterocolitis in very low birthweight infants: a prospective case-control study. Lancet. 2016; 387(10031):1928-36.

17. Torrazza RM, Neu J. The Altered Gut Microbiome and Necrotizing Enterocolitis. Clin Perinatol. 2013;40(1):93-108.

18. Hällström M, Eerola E, Vuento R, Janas M, Tammela O. Effects of mode of delivery and necrotising enterocolitis on the intestinal microflora in preterm infants. Eur J Clin Microbiol Infect Dis. 2004; 23(6):463-70.

19. OECD. Health at a Glance 2019: OECD indicators. Paris: OECD Publishing, 2019. [Accessed on January 17, 2020]. Available at: https: / / doi.org/10.1787 / 4dd50c09-en

20. Horbar JD, Edwards EM, Greenberg LT, Morrow KA, et al. Variation in Performance of Neonatal Intensive Care Units in the United States. JAMA Pediatr. 2017; 171(3):e164396.

21. Beltempo M, Lacroix G, Cabot M, Blais R, Piedboeuf B. Association of nursing overtime, nurse staffing and unit occupancy with medical incidents and outcomes of very preterm infants. J Perinatol. 2018; 38(2):175-80.

22. Watson SI, Arulampalam W, Petrou S, Marlow N, et al. The effects of a one-to-one nurse-to-patient ratio on the mortality rate in neonatal intensive care: a retrospective, longitudinal, population-based study. Arch Dis Child Fetal Neonatal Ed. 2016; 101(3):F195-200.

23. Bora R, Murthy NB. In resource limited areas complete enteral feed in stable very low birth weight infants (1000$1500 \mathrm{~g}$ ) started within $24 \mathrm{~h}$ of life can improve nutritional outcome. J Matern Neonatal Med. 2017; 30(21):2572-7.

24. Oddie SJ, Young L, Mcguire W. Slow advancement of enteral feed volumes to prevent necrotising enterocolitis in very low birth weight infants. Cochrane Database Syst Rev. 2017; 8(8):CD001241.

25. Moss RL, Kalish LA, Duggan C, Johnston P, et al. Clinical parameters do not adequately predict outcome in necrotizing enterocolitis: a multi-institutional study. J Perinatol. 2008; 28(10):665-74.

26. Tepas JJ 3rd, Leaphart CL, Plumley D, Sharma R, et al. Trajectory of Metabolic Derangement in Infants with Necrotizing Enterocolitis Should Drive Timing and Technique of Surgical Intervention. J Am Coll Surg. 2010; 210(5):847-52.

27. Yee WH, Soraisham AS, Shah VS, Aziz K, et al. Incidence and Timing of Presentation of Necrotizing Enterocolitis in Preterm Infants. Pediatrics. 2012; 129(2):e298-e304. 
ANNEX 1

General demographics of the population

\begin{tabular}{|c|c|c|c|c|c|c|c|c|}
\hline & \multirow{2}{*}{$\begin{array}{c}\text { Overall } \\
(\mathrm{n}=1428)\end{array}$} & \multirow{2}{*}{$\begin{array}{l}\text { Control } \\
(\mathrm{n}=1167)\end{array}$} & \multicolumn{2}{|c|}{ Acquiring NEC } & \multirow[b]{2}{*}{$p$} & \multirow[b]{2}{*}{$p 1^{\alpha}$} & \multirow[b]{2}{*}{$p 2^{\alpha}$} & \multirow[b]{2}{*}{$p 3^{\alpha}$} \\
\hline & & & $\begin{array}{c}\text { Suspected } \\
\text { NEC } \\
(\mathrm{n}=140)\end{array}$ & $\begin{array}{c}\text { Advanced } \\
\text { NEC } \\
(n=121)\end{array}$ & & & & \\
\hline Maternal age (years)* & $29(25-34)$ & $30(25-34)$ & $27(24-33.75)$ & $28(24-28)$ & 0.001 & 0.005 & 0.058 & 0.999 \\
\hline Maternal condition & $360(25.2 \%)$ & $300(25.7 \%)$ & $29(20.7 \%)$ & $31(25.6 \%)$ & 0.435 & 0198 & 0.983 & 0.348 \\
\hline GDM & $76(5.3 \%)$ & $65(5.6 \%)$ & $5(3.6 \%)$ & $5(5 \%)$ & 0.599 & 0.321 & 0.779 & 0.578 \\
\hline Placental conditions & $18(1.3 \%)$ & $14(1.2 \%)$ & - & $4(3.3 \%)$ & 0.212 & - & 0.081 & - \\
\hline Preeclampsy & $219(15.3 \%)$ & $183(15.7 \%)$ & $20(14.3 \%)$ & $16(13.2 \%)$ & 0.725 & 0.667 & 0.476 & 0.804 \\
\hline PROM & $70(4.9 \%)$ & $57(4.9 \%)$ & $9(6.4 \%)$ & $4(3.3 \%)$ & 0.508 & 0.439 & 0.430 & 0.248 \\
\hline SGA & $39(2.7 \%)$ & $28(2.4 \%)$ & $8(5.7 \%)$ & $3(2.5 \%)$ & 0.076 & 0.033 & 0.573 & 0.195 \\
\hline \multicolumn{9}{|l|}{ Multiple gestation } \\
\hline Twins & $194(13.6 \%)$ & $154(13.2 \%)$ & $25(17.9 \%)$ & $15(12.4 \%)$ & 0.291 & 0.130 & 0.804 & 0.222 \\
\hline Triplets & $26(1.8 \%)$ & $15(1.3 \%)$ & $2(1.4 \%)$ & $9(7.4 \%)$ & 0.001 & 0.559 & $<0.001$ & 0.016 \\
\hline \multicolumn{9}{|l|}{ Mode of delivery } \\
\hline CS delivery & $1145(80.2 \%)$ & $916(78.5 \%)$ & $118(84.3 \%)$ & $111(91.7 \%)$ & 0.001 & 0.111 & 0.001 & 0.067 \\
\hline Vaginal birth & $283(19.8 \%)$ & $251(21.5)$ & $22(15.7 \%)$ & $10(19.8 \%)$ & & & & \\
\hline \multicolumn{9}{|l|}{ Mode of conception } \\
\hline ART & $140(24.9 \%)$ & $80(6.9 \%)$ & $24(17.1 \%)$ & $36(29.8 \%)$ & $<0.001$ & $<0.001$ & $<0.001$ & 0.016 \\
\hline Outborn infant & $514(36.0 \%)$ & $417(35.7 \%)$ & $45(32.1 \%)$ & $52(43 \%)$ & 0.174 & 0.401 & 0.115 & 0.071 \\
\hline In-utero transfer & $117(8.2 \%)$ & $97(8.3 \%)$ & $6(4.3 \%)$ & $14(11.6 \%)$ & 0.095 & 0.094 & 0.226 & 0.027 \\
\hline \multicolumn{9}{|l|}{ Gender } \\
\hline Female, $(\%)$ & $631(44.2 \%)$ & $512(43.9 \%)$ & $59(42.1 \%)$ & $60(49.6 \%)$ & 0.424 & 0.697 & 0.229 & 0.229 \\
\hline Male, $(\%)$ & $797(55.8 \%)$ & $655(56.1 \%)$ & $81(57.9 \%)$ & $61(50.4 \%)$ & & & & \\
\hline GA, weeks* & $32(30-34)$ & $32(32-34)$ & $29(27-31)$ & $26(25-27)$ & $<0.001$ & $<0.001$ & $<0.001$ & $<0.001$ \\
\hline$\leq 27$ weeks & $191(13.4 \%)$ & $59(5.1 \%)$ & $40(28.6 \%)$ & $92(76 \%)$ & & & & \\
\hline 28 - 30 weeks & $215(15.1 \%)$ & $134(11.5 \%)$ & $56(40 \%)$ & $25(20.7 \%)$ & & & & \\
\hline $31-33$ weeks & $508(35.6 \%)$ & $467(40 \%)$ & $37(26.4 \%)$ & $4(3.3 \%)$ & & & & \\
\hline $34-36$ weeks & $514(36 \%)$ & $507(43.4 \%)$ & $7(5 \%)$ & - & & & & \\
\hline Birth weight, grams* & $\begin{array}{c}1760 \\
(1274-1909.2)\end{array}$ & $\begin{array}{c}1835 \\
(1620-1934)\end{array}$ & $\begin{array}{c}1120 \\
(975-1261)\end{array}$ & $\begin{array}{c}830 \\
(680-900)\end{array}$ & $<0.001$ & $<0.001$ & $<0.001$ & 0.003 \\
\hline$<750 \mathrm{~g}$ & $136(9.5 \%)$ & $76(6.5 \%)$ & $5(3.6 \%)$ & $55(45.4 \%)$ & & & & \\
\hline $751-1000 \mathrm{~g}$ & $147(10.3 \%)$ & $58(5 \%)$ & $40(28.6 \%)$ & $49(40.5 \%)$ & & & & \\
\hline $1001-1250 \mathrm{~g}$ & $132(9.2 \%)$ & $82(7 \%)$ & $42(30 \%)$ & $8(6.6 \%)$ & & & & \\
\hline $1251-1500 \mathrm{~g}$ & $147(10.3 \%)$ & $114(9.8 \%)$ & $28(20 \%)$ & $5(4.1 \%)$ & & & & \\
\hline $1501-2000 \mathrm{~g}$ & $665(46.6 \%)$ & $636(54.5 \%)$ & $25(17.9 \%)$ & $4(3.3 \%)$ & & & & \\
\hline$>2000 \mathrm{~g}$ & $201(14.1 \%)$ & $201(17.2 \%)$ & - & - & & & & \\
\hline
\end{tabular}

*Median,(interquartile range), $\alpha$ : the difference of numerical variables between three groups obtained by Kruskall Wallis and pairwise comparisons by Tamhane test; p1:difference between control and feeding intolerance, p2:difference between control and NEC groups, p3: difference between feeding intolerance - NEC groups.

Abbreviations: NEC: necrotizing enterocolitis, GDM: gestational diabetic mother; PROM: premature rupture of membranes, SGA: small for gestational age; CS delivery: caeserean sectio; ART: asisted reproductive technology; GA: gestational age, Outborn infant:born at another facility transferred to the study center due to prematurity-related problems. 


\section{ANNEX 2}

Clinical outcome of the study population

\begin{tabular}{|c|c|c|c|c|c|c|c|c|}
\hline & \multirow{2}{*}{$\begin{array}{c}\text { Overall } \\
(n=1428)\end{array}$} & \multirow{2}{*}{$\begin{array}{c}\text { Control } \\
(\mathrm{n}=1167)\end{array}$} & \multicolumn{2}{|c|}{ Acquiring NEC } & \multirow[b]{2}{*}{$p$} & \multirow[b]{2}{*}{$p 1^{\alpha}$} & \multirow[b]{2}{*}{$p 2$} & \multirow[b]{2}{*}{$p 3$} \\
\hline & & & $\begin{array}{c}\text { Suspected } \\
\text { NEC } \\
(\mathrm{n}=140)\end{array}$ & $\begin{array}{c}\text { Advanced } \\
\text { NEC } \\
(n=121)\end{array}$ & & & & \\
\hline Antenatal steroid & $847(59.3 \%)$ & $714(61.2 \%)$ & $77(55 \%)$ & $56(46.3 \%)$ & 0.004 & 0.157 & 0.001 & 0.160 \\
\hline Postnatal steroid & $116(8.1 \%)$ & $54(4.6 \%)$ & $19(13.6 \%)$ & $43(35.5 \%)$ & $<0.001$ & $<0.001$ & $<0.001$ & $<0.001$ \\
\hline 5-min Apgar score & $184(12.9 \%)$ & $129(11.1 \%)$ & $15(10.7 \%)$ & $40(33.1 \%)$ & $<0.001$ & 0.903 & $<0.001$ & $<0.001$ \\
\hline Resuscitation at birth & $201(14.1 \%)$ & $158(13.5 \%)$ & $21(15 \%)$ & $22(18.2 \%)$ & 0.356 & 0.635 & 0.161 & 0.490 \\
\hline RDS & $233(16.3 \%)$ & $99(8.5 \%)$ & $49(35 \%)$ & $85(70.2 \%)$ & $<0.001$ & $<0.001$ & $<0.001$ & $<0.001$ \\
\hline Invasive MV & $403(28.2 \%)$ & $236(20.2 \%)$ & $64(45.7 \%)$ & $103(85.1 \%)$ & $<0.001$ & $<0.001$ & $<0.001$ & $<0.001$ \\
\hline Length of MV (days)* & $6(4-9)$ & $4.5(3-8)$ & $6(4-8)$ & $9(7-16)$ & $<0.001$ & 0.123 & $<0.001$ & $<0.001$ \\
\hline CPAP therapy & $680(47.6 \%)$ & $551(47.2 \%)$ & $57(40.7 \%)$ & $72(59.5 \%)$ & 0.008 & 0.145 & 0.010 & 0.002 \\
\hline Length of CPAP (days)* & $6(3-11)$ & $4(2-8)$ & $9(5-12.75)$ & $12.5(8-18)$ & $<0.001$ & $<0.001$ & $<0.001$ & 0.999 \\
\hline Sepsis & $124(8.7 \%)$ & $62(5.3 \%)$ & $22(15.7 \%)$ & $40(33.1 \%)$ & $<0.001$ & $<0.001$ & $<0.001$ & 0.001 \\
\hline PDA $(\%)$ & $154(10.8 \%)$ & $52(4.5 \%)$ & $52(37.1 \%)$ & $50(41.3 \%)$ & $<0.001$ & $<0.001$ & $<0.001$ & 0.490 \\
\hline CHD other than PDA & $74(5.2 \%)$ & $62(5.3 \%)$ & $3(2.1 \%)$ & $9(7.4 \%)$ & 0.140 & 0.103 & 0.330 & 0.059 \\
\hline IVH & $114(8.0 \%)$ & $35(3.0 \%)$ & $22(15.7 \%)$ & $57(47.1 \%)$ & $<0.001$ & $<0.001$ & $<0.001$ & $<0.001$ \\
\hline \multicolumn{9}{|c|}{ Nutrition outcome } \\
\hline First enteral feeding (day & )$^{*} 1(1-2)$ & $1(1-2)$ & $3(2-3)$ & $3(2-4)$ & $<0.001$ & $<0.001$ & $<0.001$ & 0.007 \\
\hline Preterm formula & $297(20.8 \%)$ & $234(20.1 \%)$ & $32(22.9 \%)$ & $31(25.6 \%)$ & 0.292 & 0.436 & 0.149 & 0.603 \\
\hline $\begin{array}{l}\text { Age onset of } \\
\text { symptoms (day)* }\end{array}$ & $13(11-16)$ & - & $13(11-14)$ & $18(16-20)$ & $<0.001$ & - & - & $<0.001$ \\
\hline Duration of fasting (days & )$^{*} 8(5-13)$ & - & $6(5-8)$ & $13(11-16)$ & $<0.001$ & - & - & $<0.001$ \\
\hline Parenteral nutrition (days & )$^{*} 16(11-20)$ & $10(8-11)$ & $20(18-25)$ & $32(27-35)$ & $<0.001$ & $<0.001$ & $<0.001$ & $<0.001$ \\
\hline NICU stay (days)* & $16(9-36)$ & $15(8-23)$ & $53(41-66.75)$ & $73(27-97)$ & $<0.001$ & $<0.001$ & $<0.001$ & 0.002 \\
\hline Mortality & $129(9.0 \%)$ & $89(7.6 \%)$ & $7(5.0 \%)$ & $33(27.3 \%)$ & $<0.001$ & 0.260 & $<0.001$ & $<0.001$ \\
\hline \multicolumn{9}{|c|}{ Laboratory diagnostics } \\
\hline Hematocrit (\%) & $\begin{array}{c}42.3 \\
(34.4-50.5)\end{array}$ & $\begin{array}{c}45.2 \\
(35.4-51.1)\end{array}$ & $\begin{array}{c}44.4 \\
(35.1-50.5)\end{array}$ & $\begin{array}{c}41.2 \\
(32.8-47.2)\end{array}$ & 0.098 & 0.773 & 0.121 & 0.564 \\
\hline $\mathrm{WBC}\left(\times 10^{9} / \mathrm{L}\right)$ & $\begin{array}{c}15.2 \\
(12.6-18.3)\end{array}$ & $\begin{array}{c}14.8 \\
(12.4-18.1)\end{array}$ & $\begin{array}{c}15.8 \\
(13.3-18.4)\end{array}$ & $\begin{array}{c}18.38 \\
(15.1-23.3)\end{array}$ & $<0.001$ & 0.159 & $<0.001$ & $<0.001$ \\
\hline Leukocytosis & $211(14.8 \%)$ & $152(13 \%)$ & $13(9.3 \%)$ & $46(38 \%)$ & $<0.001$ & 0.208 & $<0.001$ & $<0.001$ \\
\hline Leukopenia & $36(2.5 \%)$ & $30(2.6 \%)$ & $2(1.4 \%)$ & $4(3.3 \%)$ & 0.608 & - & - & - \\
\hline Platelets $\left(\times 10^{9} / \mathrm{L}\right)$ & $\begin{array}{c}218 \\
(175-294.5)\end{array}$ & $\begin{array}{c}228.5 \\
(171-338.5)\end{array}$ & $\begin{array}{c}218.5 \\
(179-275)\end{array}$ & $\begin{array}{c}198 \\
(151-290)\end{array}$ & 0.115 & 0.673 & 0.160 & 0.531 \\
\hline Thrombocytopenia & $37(2.6 \%)$ & $14(1.2 \%)$ & $4(2.9 \%)$ & $19(15.7 \%)$ & 0.001 & 0.484 & 0.003 & $<0.001$ \\
\hline $\mathrm{CRP}(\mathrm{mg} / \mathrm{dL})$ & $\begin{array}{c}1.1 \\
(0.69-1.86)\end{array}$ & $\begin{array}{c}0.96 \\
(0.69-1.62)\end{array}$ & $\begin{array}{c}1.19 \\
(0.75-1.97)\end{array}$ & $\begin{array}{c}1.02 \\
(1.00-1.99)\end{array}$ & 0.310 & 0.147 & 0.133 & 0.980 \\
\hline Metabolic acidosis & $122(8.5 \%)$ & $3(0.3 \%)^{\mathrm{a}}$ & $31(22.1 \%)^{b}$ & $88(72.7 \%)^{c}$ & $<0.001$ & $<0.001$ & $<0.001$ & $<0.001$ \\
\hline
\end{tabular}

*median (interquartile range); statistics for numerical variables obtained by Kruskall Wallis and pairwise comparisons by Tamhane test; p1: control - suspected NEC groups p2: control - advanced NEC groups, p3: suspected NEC - advanced NEC groups. Abbreviations: NEC: necrotizing enterocolitis; RDS: respiratory distress syndrome; MV: mechanical ventilation; CPAP: continuous positive airway pressure; PDA: patent ductus arteriosus; CHD: congenital heart disease;

IVH: intraventricular hemorrhage; NICU: neonatal intensive care unit; WBC: White blood cell count, leukocytosis: wbc $>20 \times 10^{\circ} / \mathrm{L}$; leukopenia: wbc $<5 \times 10^{9} / \mathrm{L}$; thrombocytopenia: platelets $<100 \times 10^{9} / \mathrm{L}$;

CRP: C-reactive protein; metabolic acidosis ( $\mathrm{ph}<7.35$ and base deficit $>-5$ ). 
ANNEX 3

The demographics and clinical outcome of GI perforations

\begin{tabular}{|c|c|c|c|c|}
\hline & Acq & NEC & & \\
\hline & $\begin{array}{l}\text { Non-perforations } \\
\quad(n=214)\end{array}$ & $\begin{array}{l}\text { Perforations } \\
(n=47)\end{array}$ & OR $(95 \%$ CI $)$ & $P$ \\
\hline Male gender & $119(55.6 \%)$ & $23(48.9 \%)$ & $1.307(0.695-2.460)$ & 0.406 \\
\hline Maternal age, (years)* & $28(24-34)$ & $27(23-32)$ & $0.984(0.935-1.036)$ & 0.539 \\
\hline Maternal condition & $52(24.3 \%)$ & $8(17 \%)$ & $0.639(0.281-1.454)$ & 0.283 \\
\hline GDM & $11(5.1 \%)$ & - & - & NA \\
\hline Placental condition & $4(1.9 \%)$ & - & - & NA \\
\hline Preeclampsy & $31(14.5 \%)$ & $5(10.6 \%)$ & $0.703(0.258-1.915)$ & 0.489 \\
\hline PROM & $9(4.2 \%)$ & $4(8.5 \%)$ & $2.119(0.629-7.197)$ & 0.189 \\
\hline SGA & $10(4.7 \%)$ & $1(2.1 \%)$ & $0.443(0.55-3.551)$ & 0.444 \\
\hline ART & $49(22.9 \%)$ & $11(23.4 \%)$ & $1.029(0.488-2.171)$ & 0.379 \\
\hline CS delivery & $187(87.4 \%)$ & $42(89.4 \%)$ & $1.213(0.441-3.334)$ & 0.708 \\
\hline In-utero transport & $12(5.6 \%)$ & $8(17 \%)$ & $3.453(1.325-9.000)$ & 0.014 \\
\hline Outborn infant & $73(34.1 \%)$ & $24(51.1 \%)$ & $2.015(1.065-3.814)$ & 0.029 \\
\hline Multiple gestation & & & & \\
\hline Twins & $33(15.4 \%)$ & $7(14.9 \%)$ & $0.960(0.396-2.325)$ & 0.928 \\
\hline Triplet & $6(2.8 \%)$ & $5(1.6 \%)$ & - & NA \\
\hline Gestational age, (weeks) & $27.96 \pm 2.26$ & $25.87 \pm 1.99$ & & 0.001 \\
\hline$\leq 27$ weeks & $98(47.7 \%)$ & $34(72.3 \%)$ & $2.872(1.436-5.744)$ & 0.003 \\
\hline 28 - 30 weeks & $68(31.7 \%)$ & $13(27.7 \%)$ & $0.770(0.383-1.550)$ & 0.463 \\
\hline $31-33$ weeks & $41(19.2 \%)$ & - & - & NA \\
\hline $34-36$ weeks & $7(3.3 \%)$ & - & - & NA \\
\hline Birth weight (grams) & $1021.75 \pm 206.06$ & $722.02 \pm 139.88$ & & $<0.001$ \\
\hline$<750 \mathrm{~g}$ & $34(15.9 \%)$ & $26(55.3 \%)$ & $12.010(5.760-25.080)$ & $<0.001$ \\
\hline $751-1000 \mathrm{~g}$ & $75(35.1 \%)$ & $14(29.9 \%)$ & $1.031(0.546-1.946)$ & 0.425 \\
\hline $1001-1250 \mathrm{~g}$ & $45(21 \%)$ & $5(10.6 \%)$ & - & 0.646 \\
\hline $1251-1500 \mathrm{~g}$ & $31(14.5 \%)$ & $2(4.3 \%)$ & - & 0.547 \\
\hline $1500-2000 \mathrm{~g}$ & $29(13.6 \%)$ & - & - & NA \\
\hline Clinical outcome & & & & \\
\hline Antenatal steroids & $113(52.8 \%)$ & $20(42.6 \%)$ & $0.662(0.350-1.252)$ & 0.203 \\
\hline Postnatal steroids & $43(20.1 \%)$ & $19(40.4 \%)$ & $2.699(1.379-5.282)$ & 0.003 \\
\hline Resuscitation & $37(17.3 \%)$ & $6(12.8 \%)$ & $0.700(0.277-1.769)$ & 0.449 \\
\hline Low 5-minutes Apgar & $33(15.4 \%)$ & $22(46.8 \%)$ & $4.827(2.439-9.552)$ & $<0.001$ \\
\hline RDS & $97(45.3 \%)$ & $37(78.7 \%)$ & $4.463(2.111-9.435)$ & 0.001 \\
\hline Invasive MV & $123(57.5 \%)$ & $44(93.6 \%)$ & $10.851(3.267-36.045)$ & $<0.001$ \\
\hline Length of MV (days)* & $7(5-10)$ & $11(7.25-22.5)$ & $1.153(1.086-1.224)$ & $<0.001$ \\
\hline CPAP therapy & $115(53.7 \%)$ & $14(29.8 \%)$ & $0.365(0.185-0.721)$ & 0.003 \\
\hline Length of CPAP (days) * & $13(9-18)$ & $21.5(15.5-26.75)$ & $1.114(1.048-1.184)$ & 0.001 \\
\hline Sepsis & $43(20.1 \%)$ & $19(40.4 \%)$ & $2.699(1.379-5.282)$ & 0.003 \\
\hline PDA & $77(36 \%)$ & $25(53.2 \%)$ & $2.022(1.069-3.824)$ & 0.029 \\
\hline CHD other than PDA $(\%)$ & $5(2.3 \%)$ & $7(14.9 \%)$ & - & NA \\
\hline IVH & $56(26.2 \%)$ & $23(48.9 \%)$ & $2.704(1.414-5.169)$ & 0.002 \\
\hline Nutrition & & & & \\
\hline Timing of first enteral feeding, (day) & r)* $3(2-4)$ & $3(2-4)$ & $1.092(0.784-1.520)$ & 0.604 \\
\hline Undiluted preterm formula & $48(22.4 \%)$ & $15(31.9 \%)$ & $1.621(0.811-3.240)$ & 0.169 \\
\hline Age onset of GI symptom, (day) ${ }^{*}$ & $14(11-16)$ & $19(17-21)$ & $1.479(1.305-1.675)$ & $<0.001$ \\
\hline Duration of fasting, (days) ${ }^{*}$ & $10(7-12)$ & $16(13-18)$ & $1.679(1.439-1.958)$ & $<0.001$ \\
\hline Parenteral nutrition, (days)* & $16(14-17)$ & $34(32.5-35)$ & $1.230(1.121-1.350)$ & $<0.001$ \\
\hline Diagnostic work-up & & & & \\
\hline Hematocrit $(\%)$ * & $44.9(35.4-50.72)$ & $43.9(35.1-50.7)$ & $1.004(0.971-1.038)$ & 0.810 \\
\hline Leukocytosis & $34(15.9 \%)$ & $25(53.2 \%)$ & $6.016(3.047-11.877)$ & $<0.001$ \\
\hline Leukopenia & $4(1.9 \%)$ & $2(4.3 \%)$ & $2.33(0.415-13.131)$ & 0.295 \\
\hline Platelet counts $\left(\times 10^{9} / \mathrm{L}\right)$ & $211(178-286)$ & $194(92-290)$ & $0.997(0.994-1.001)$ & 0.086 \\
\hline Thrombocytopenia & $10(4.7 \%)$ & $13(27.7 \%)$ & $7.800(3.169-19.200)$ & $<0.001$ \\
\hline $\mathrm{CRP}(\mathrm{mg} / \mathrm{dl})^{*}$ & $0.80(0.60-1.72)$ & $1.19(0.70-2.03)$ & $0.859(0.671-1.099)$ & 0.049 \\
\hline Metabolic acidosis & $72(33.6 \%)$ & $47(100 \%)$ & $1.653(1.429-1.911)$ & $<0.001$ \\
\hline
\end{tabular}

-Odds ratios obtained by binary regression if $\mathrm{p}<0.05$; ${ }^{*}$ median (interquartile range);

NA: not applicable due to small number of group population.

-Leukopenia: $\mathrm{wbc}<5 \times 10^{9} / \mathrm{L}$, leukocytosis: $\mathrm{wbc}>20 \times 10^{9} / \mathrm{L}$, thrombocytopenia: platelets $<100 \times 10^{9}$.

Abbreviations: GDM: gestational diabetic mother; PROM: premature rupture of membranes, SGA: small for gestational age; ART: asisted reproductive technology; CS delivery: caeserean sectio; GA: gestational age, RDS: respiratory distress syndrome; MV: mechanical ventilation; CPAP: continuous positive airway pressure; PDA: patent ductus arteriosus;

CHD: congenital heart disease; IVH: intraventricular hemorrhage, WBC: White blood cell count, leukocytosis: wbc $>20 \times 10^{9} / \mathrm{L}$; leukopenia: wbc $<5 \times 10^{9} / \mathrm{L}$; thrombocytopenia: platelets $<100 \times 10^{9} / \mathrm{L}$; CRP: C-reactive protein; metabolic acidosis ( $\mathrm{ph}<7.35$ and base deficit $>-5)$. 